\title{
Analysis on Dynamic Response of Prestressed Concrete Slab Subjected to Blast Loading
}

\author{
Chongxi Bai \\ School of Water Conservancy \& Civil Engineering, Northeast Agricultural University, Harbin, Heilongjiang 150030, China
}

\begin{abstract}
The dynamic response of prestressed concrete slab under blast loading was analyzed based on LS-DYNA. The laws of influence of degree of prestress, combined reinforcement index, weight of explosives, thickness of slab on the dynamic response of prestressed concrete slab under blast loading were discussed, and the failure modes were given. The analysis results showed that the peak displacement at midspan increased with increasing of degree of prestress and weight of explosives, and reduced with increasing of combined reinforcement index and thickness of slab. All the parameters, the influence of weight of explosives on displacement response of slab was significantly. Rationalization proposals were provided for blast resistant design of prestressed concrete slab.
\end{abstract}

\section{Introduction}

How to effectively prevent the occurrence of structural damage and collapse under various explosion loads, as well as how to improve the ability of blast resistant and protection for all kinds of building structures, has become an important and urgent task faced by the field of civil engineering. As early as half a century ago, scholars began to study the principle of explosion, and carried out a series of related researches.

Mavier [1], an American scholar, studied the dynamic behavior of reinforced concrete members subjected to blast loading. The results of this study have been widely used in structural response analysis of structures. $\mathrm{Xu}$ [2], based on the LS-DYNA program, studied the concrete cracking process of reinforced concrete slab under blast loading, and established the concrete failure criterion. Low [3], based on the two single degree of freedom systems with relaxation coupling, studied the flexural and direct shear effects of reinforced concrete slabs under blast loading, and predicted the possibility of structural failure. The numerical simulation of the dynamic response of reinforced concrete slabs subjected to blast loading was carried out by Gong [4]. Based on the Timoshenko beam theory, the failure modes and influencing factors of reinforced concrete beams under blast loading were analyzed by Fang [5].

The experimental study on the influence of explosion on the structure has many limitations, such as complex operation, high risk, complex simulation and so on. With the development of computer technology, the finite element method has been applied in the field of blast response analysis. LS-DYNA finite element calculation module in ANSYS software can be used for transient analysis. Therefore, based on LS-DYNA, dynamic response analysis of prestressed concrete slab under blast loading, has an important guiding significance for the blast resistant design.

\section{Classification of members}

For the analysis of dynamic response of prestressed concrete slab under explosion load, the simulation program was developed based on LS-DYNA software, and the results of the simulation program were also compared with the experimental ones [6]. The results showed that the dynamic response of prestressed concrete flexural member under blasting load can be analyzed effectively by numerical simulation program effective, with a certain precision.

Taking the $1 \mathrm{~m}$ wide prestressed concrete simply supported slab as the standard member, the span of the slab was $2.84 \mathrm{~m}$, and the thickness of the slab was $120 \mathrm{~mm}$. The design strength grade of concrete was C40, and the non prestressed reinforcement was HPB300 grade steel, and the prestressed steel was made of medium strength prestressed steel wire, and the yield strength was $980 \mathrm{MPa}$. The distance between the center of the explosion and the center of the prestressed concrete simply supported slab $R$ was $1.5 \mathrm{~m}$, and TNT weight $W$ was $3.38 \mathrm{~kg}$, and the equivalent distance of explosive load was 1 . The combined reinforcement index of critical section of mid-span $\beta_{0}$ was 0.3 , and the degree of prestress $\lambda$ was 0.67 . The prestressed reinforcement index $\beta_{\mathrm{p}}$ was 0.2 , and the non prestressed reinforcement index $\beta_{\mathrm{s}}$ was 0.1 .

With the reinforcement index instead of the strength and area of reinforcement, concrete strength, section width and thickness and other factors, the influence of these factors on the dynamic response of prestressed concrete slab were reflected comprehensively. The

\footnotetext{
*Corresponding author's e-mail: bcxzcx@163.com
} 
reinforcement index was calculated according to the following equations (1), (2), (3).

$$
\begin{aligned}
& \beta_{0}=\beta_{\mathrm{p}}+\beta_{\mathrm{s}} \\
& \beta_{\mathrm{p}}=\frac{A_{\mathrm{p}} \sigma_{\mathrm{pe}}}{b h_{\mathrm{p}} f_{\mathrm{c}}} \\
& \beta_{\mathrm{s}}=\frac{A_{\mathrm{s}} f_{\mathrm{y}}}{b h_{\mathrm{p}} f_{\mathrm{c}}}
\end{aligned}
$$

Where, $\sigma_{\mathrm{pe}}$ is effective prestress of prestressed tendons $\left(\mathrm{N} / \mathrm{mm}^{2}\right) ; A_{\mathrm{p}}$ is area of prestressed tendons $\left(\mathrm{mm}^{2}\right) ; b$ is width of the section $(\mathrm{mm}) ; h_{\mathrm{p}}$ is distance between the prestressed reinforcement and the compression extreme fiber of the section $(\mathrm{mm}) ; f_{\mathrm{c}}$ is axial compressive strength of concrete $\left(\mathrm{N} / \mathrm{mm}^{2}\right)$.

\section{Parameter analysis}

\subsection{Damage modes}

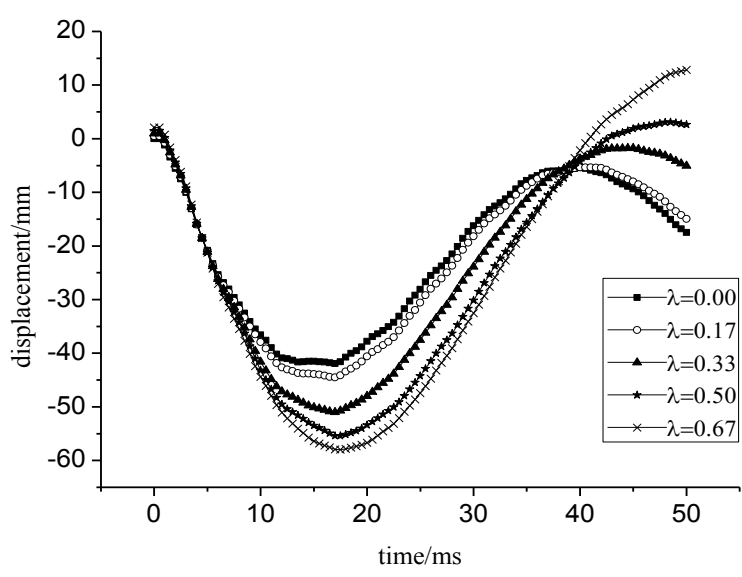

Figure 1: Effect of prestress degree on displacement time history curve of mid-span joint

It can be seen from figure 1 and figure 2 that, in the early stage of the explosion, there was no influence of prestress degree on the variation of displacement of the mid-span joint. Then, prestress degree had a great influence on the variation of displacement of the midspan joint, that was, displacement of the mid-span joint increased with the increase of prestress degree. The time to reach the peak displacement of the mid-span joint was roughly equal under the different prestress degree. After each joint reached the peak displacement, the displacement decreased gradually, and the displacement of each joint was approximately the same as $t=38 \mathrm{~ms}$. The amplitude of vibration of slab increased with the increase of prestress degree; reinforcement ratio decreased because of increasing of prestress degree for the same combined reinforcement index, and the stiffness of the slab reduced because of decreasing of reinforcement ratio, so the amplitude of vibration of the slab was significantly larger. The peak displacement at mid-span joint increased with the increase of the prestress degree, and relationship was generally linear.
By analyzing of the axial stress of reinforcement element, effective plastic strain and stress of concrete element, it can be seen that cracks have appeared in the bottom and the top surface of the slab, and prestressed tendons and non prestressed tendons yielded in mid-span, and the concrete in the compression zone has been crushed, and the supporting concrete failed by shear. Therefore, flexural failure and shear failure happened for standard members under explosion load at the same time.

\subsection{The influence of degree of prestress}

To investigate the influence of degree of prestress on the dynamic performance of the prestressed slab, the other factors were kept constant, and the prestress $\lambda$ was taken as the values of $0,0.17,0.33,0.67$, respectively. The curves of the displacement at mid-span of prestressed concrete slab with time under different prestress degree were as shown in figure 1. The relationship of peek displacement at mid-span and prestressed degree was as shown in figure 2.

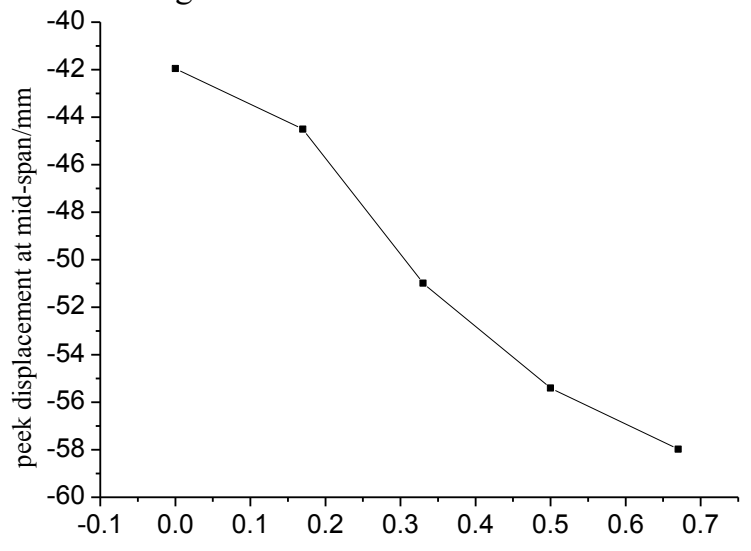

Figure 2: The relationship of peek displacement at midspan and prestressed degree

\subsection{The influence of combined reinforcement index}

To investigate the influence of the reinforcement index on the dynamic performance of the prestressed slab, the other factors were kept constant, and the combined reinforcement index of cross section $\beta_{0}$ was taken as the values of $0.20,0.25,0.30,0.35,0.40$, respectively. The curves of the displacement of the mid-span joint of the prestressed concrete slab with time under different combined reinforcement index were as shown in figure 3 . The relationship of peek displacement at mid-span and combined reinforcement index was as shown in figure 4.

It can be seen from figure 3 and figure 4 that, in the early stage of the explosion, there was no influence of combined reinforcement index on the variation of displacement of the mid-span joint. Then, combined reinforcement index had great influence on the variation of displacement of the mid-span joint, that was, displacement of the mid-span joint decreased with the increase of combined reinforcement index. The time of reaching the peak displacement of the mid-span joint decreased with the increase of the combined 
reinforcement index, and the displacement decreased gradually after each joint reached the peak displacement. The peak displacement of the mid-span joint decreased with the increase of the combined reinforcement index,

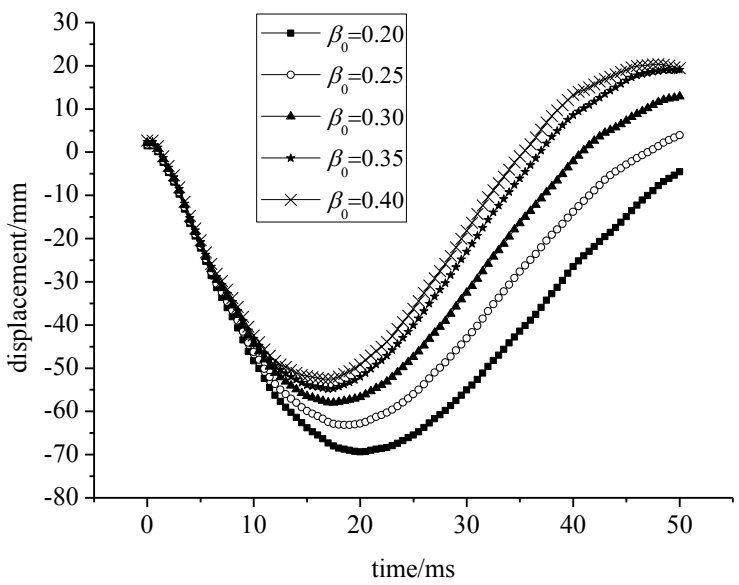

Figure 3: Effect of combined reinforcement index on displacement time history curve of mid-span joint

\subsection{The influence of explosive weight}

To investigate the effect of explosive weight on the dynamic performance of prestressed slab, the other factors were kept constant, the weight of TNT $W$ was taken as the values of $8.00 \mathrm{~kg}, 3.38 \mathrm{~kg}, 1.73 \mathrm{~kg}, 1.00 \mathrm{~kg}$, $0.63 \mathrm{~kg}$, respectively, and the corresponding explosion

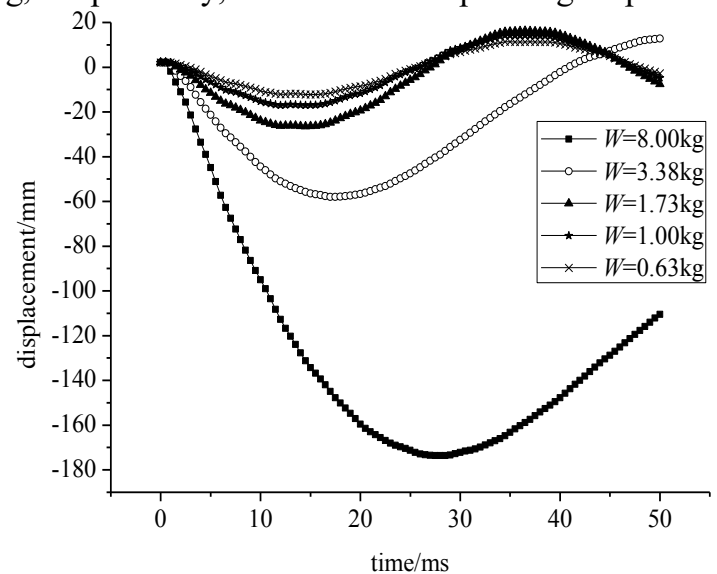

Figure 5: Effect of explosive weight on displacement time history curve of mid-span joint

It can be seen from figure 5 and figure 6 that, displacement decreased with increasing the weight of the explosive; displacement of slab for explosive weight $W=8.00 \mathrm{~kg}, W=3.38 \mathrm{~kg}$ were larger than that of the rest of three kinds of explosive weight slab, and the displacement of $8.00 \mathrm{~kg}$ explosive weight slab was the most prominent. In fact, in the premise of unchanging distance between explosive and slab, increasing explosive weight was equivalent to reduce equivalent distance of explosive, so the displacement performance of prestressed slab under explosion load increased significantly, which was consistent with the experimental results. Vibration effect occurred for $1.73 \mathrm{~kg}, 1.00 \mathrm{~kg}$, $0.63 \mathrm{~kg}$ explosive weight slabs within $50 \mathrm{~ms}$. The peak and was approximately linear. Because of increase of the stiffness of the slab with the increase of the combined reinforcement index, the peak displacement of the slab with large combined reinforcement index was small.

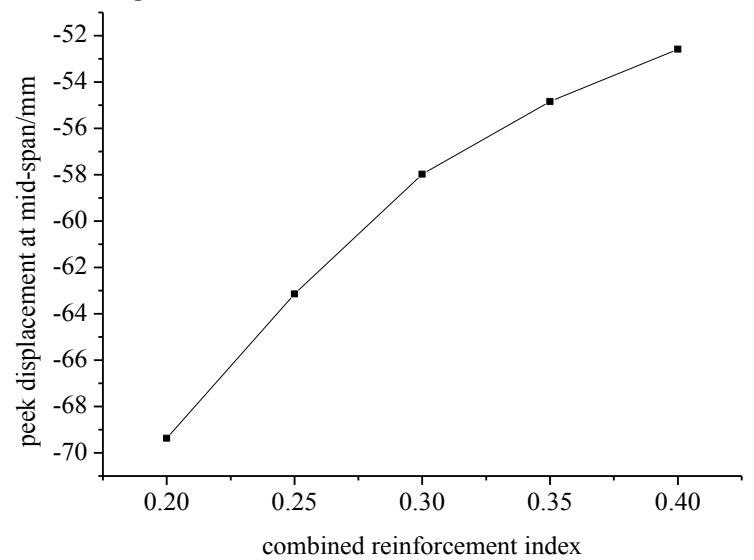

Figure 4: The relationship of peek displacement at midspan and combined reinforcement index

equivalent distance was $0.75 \mathrm{~kg} / \mathrm{m}^{1 / 3}, \quad 1.00 \mathrm{~kg} / \mathrm{m}^{1 / 3}$, $1.25 \mathrm{~kg} / \mathrm{m}^{1 / 3}, 1.50 \mathrm{~kg} / \mathrm{m}^{1 / 3}, 1.75 \mathrm{~kg} / \mathrm{m}^{1 / 3}$, respectively. The curves of the displacement of the mid-span joint of the prestressed concrete slab with time under different explosive weight were as shown in figure 5. The relationship of peek displacement at mid-span and explosive weight was as shown in figure 6 .

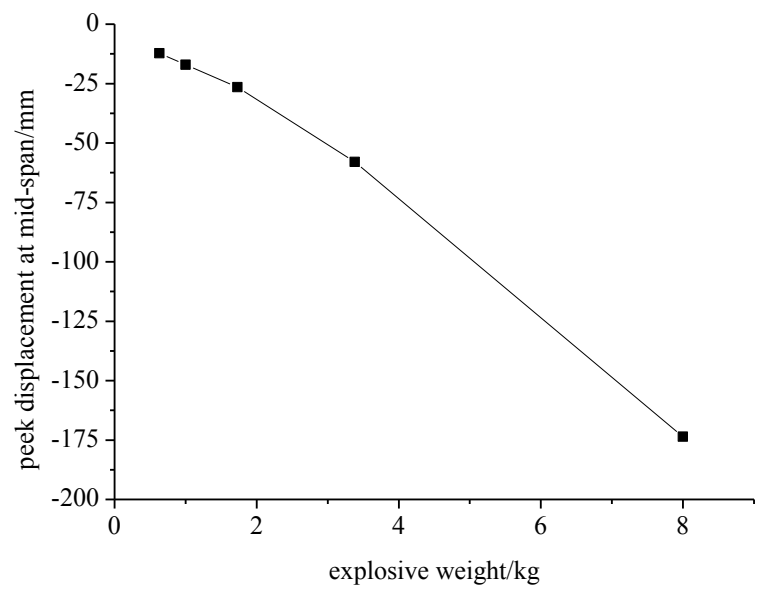

Figure 6: The relationship of peek displacement at mid-span and explosive weight

displacement of the mid-span joint increased with the increase of the explosive weight, and changed linearly.

\subsection{The influence of slab thickness}

To investigate the influence of the thickness of the slab on the dynamic performance of the prestressed concrete slab, the other factors were kept constant, and the thickness of slab $h$ was taken as the values of $120 \mathrm{~mm}$. $160 \mathrm{~mm} 、 200 \mathrm{~mm}$ respectively. The curves of the displacement of the mid-span joint of the prestressed concrete slab with time under different slab thickness were as shown in figure 7 . The relationship of peek displacement at mid-span and thickness of slab was as shown in figure 8 . 


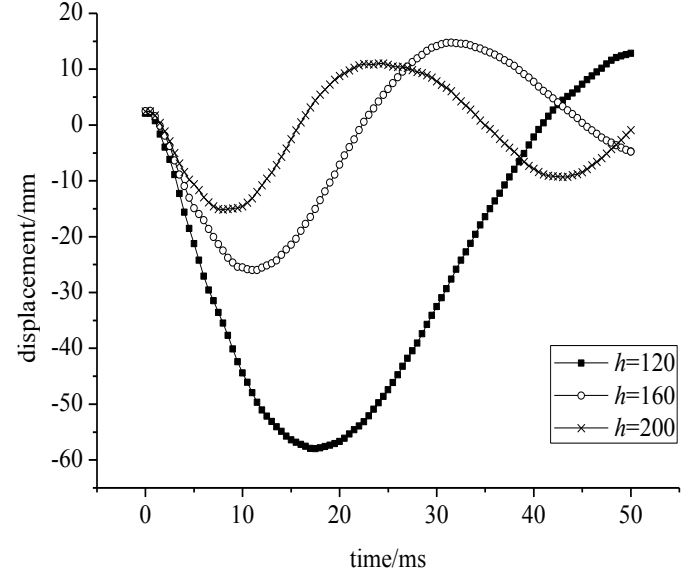

Figure 7: Effect of slab thickness on displacement time history curve of mid-span joint

It can be seen from figure 7 and figure 8 that, the displacement decreased with the increase of the slab thickness before from 0 to peak displacement, and the peek displacement at mid-span of the slab decreased with the increase of the slab thickness. The arrival time of the peak displacement decreased with the increase of the slab thickness. In fact, the increase of the slab thickness was equivalent to increase the stiffness of the slab, so the displacement response of the slab decreased with the increase of the thickness of the slab, which was consistent with the experimental results. Vibration effect occurred for $120 \mathrm{~mm}, 160 \mathrm{~mm}$ thickness slabs within $50 \mathrm{~ms}$.

\section{Conclusions}

The flexural failure and shear failure of the standard member under explosive load happened at the same time. The peak displacement at the mid-span joint increased with the increase of the prestress degree; decreased with the increase of the combined reinforcement index; increased with the increase of the explosive weight; decreased with the increase of the slab thickness. In addition, the weight of the explosive had a significant effect on the displacement response of the slab. In the prestressed concrete slab with small explosive weight ( $W=0.63 \mathrm{~kg}$ ), the stress of non prestressed tendon was not up to the tensile yield strength, and the compressive strength of concrete was not up to compressive strength, along with shear failure. For the remaining explosives weight and other factors, the flexural failure and shear failure of the prestressed concrete slab both occurred.

\section{Acknowledgments}

This work was supported by the National Natural Science Foundation of China (No. 51608101), the Natural Science Foundation of Heilongiiang Province of China (No. E2017008), and the Heilongjiang Provincial Postdoctoral Research Funding Program (No. LBHQ16030).

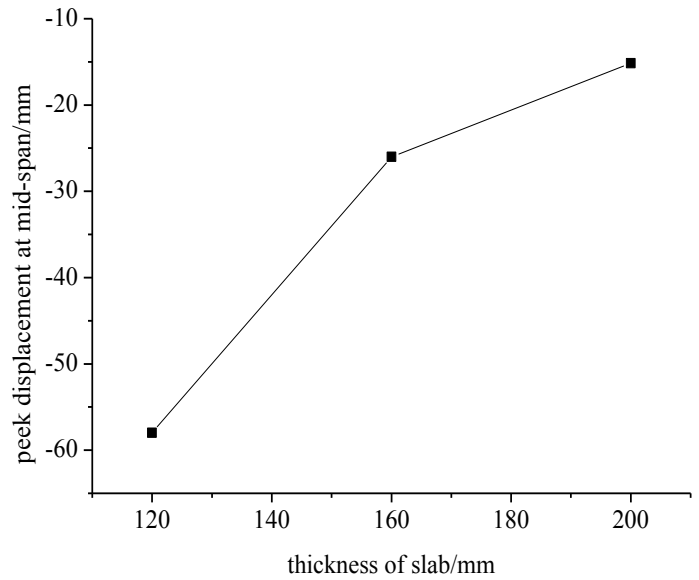

Figure 8: The relationship of peek displacement at midspan and thickness of slab

\section{References}

1. Malvar, L. J. (1998) Review of static and dynamic properties of steel reinforceing bars. ACI Materials Journal, 95: 609-616.

2. Xu, K., Lu, Y. (2006) Numerical simulation study of spallation in reinforced concrete plates subjected to blast loading. Computers \& Structures, 84: 431-438.

3. Low, H. Y., Hao, H. (2002) Reliability analysis of direct shear and flexural failure modes of RC slabs under explosive loading. Engineering Structures, 24: 189-198.

4. Gong, S. F., Zhu, S. B., Zhang, A. H., et al. (2011) Numerical simulation of blast loads and dynamic response of reinforced concrete slab subjected to close-in explosion. Journal of Beijing University of Technology, 37: 199-205.

5. Fang, Q., Wu, P. A. (2003) Analysis of the Main factors affecting failure modes of blast loaded RC beams. Chinese Journal of Computational Mechanics, 20: 39-42, 48.

6. Sun, W. B. (2009) Experimental studies on reinforced concrete (RC) slabs subjected to blast loads. Journal of Liaoning Technical University (Natural Science), 28: 217-220. 